\title{
Apresentação da coletânea. Atualidades do cooperativismo brasileiro
}

doi: http://dx.doi.org/10.18543/dec-17-2021pp11-13

Convergente com a expressividade dos números do Cooperativismo na economia brasileira, pode-se afirmar que o envolvimento acadêmico e científico com a matéria cooperativa cresceu de forma exponencial, conquistando o espaço na conformação de políticas pedagógicas e de pesquisa de muitas entidades universitárias. Por tudo isto, entende-se relevante a oportunidade que a Revista Deusto Estudios Cooperativos oferece aos pesquisadores brasileiros, para veicularem seus estudos sobre assuntos que merecem destaque literário e investigativo.

Neste sentido, destaca-se que o presente número reúne exponenciais acadêmicos e profissionais do Cooperativismo brasileiro. São atores cooperativos vinculados à distintas Instituições de Ensino Superior. Todos, de uma ou de outra forma, associam a cooperatividade tanto ao seu exercício funcional, como à sua atividade científico-acadêmica. No momento em que cada um deles recebeu o contato, informando o convite e a oportunidade que o Instituto de Estudios Cooperativos da Faculdade de Direito, da Universidad de Deusto, oferecia ao Cooperativismo brasileiro para socializar em larga escala a mais recente produção em matéria cooperativa, todos foram firmes e agradecidos em responder positivamente ao ensejo.

É desta forma que o presente número reúne oito trabalhos, com tema atuais previamente selecionados, e cujos artigos foram elaborados com muito esmero e dedicação.

O primeiro artigo, assinado pelo signatário e pela Bacharela Victória Corrêa Lima, sob o título Do Processo de Formação Da Legislação Cooperativa Brasileira à Atualidade das Cooperativas Agrícolas e de Consumo: A Nova Estrutura do Cooperativismo Brasileiro, faz um recorrido pelo processo histórico de desenvolvimento da legislação cooperativa brasileira, dando ênfase às principais peculiaridades das cooperativas 
agropecuárias e de consumo, além de apresentar a atual estrutura dos ramos cooperativos no Brasil.

Como segundo, tem-se a produção da Professora Giselle Borges Alves, que leva o título Incidência de Normas Concorrenciais em Cooperativas: A Intervenção Estatal Sobre Cooperativas no Brasil, e analisa as decisões do Conselho Administrativo de Defesa Econômica, em relação às atividades levadas a termo pelas cooperativas brasileiras, sobrelevando que a garantia constitucional de não intervenção do Estado não presume que as cooperativas estejam imunes à aplicação da legislação antitruste.

Em terceiro, a Professora Marianna Ferraz Teixeira, com a produção A Indevida Aplicação do Enunciado de Súmula N. 281 Do Tribunal de Contas da União e a Proibição Da Participação de Cooperativas de Trabalho Brasileiras em Procedimentos Licitatórios, transita pelo enunciado da Súmula n. 281, do Tribunal de Contas da União, aprovada em 11 de julho de 2012, para minudenciar o veto à participação das cooperativas de trabalho em licitações, na hipótese de que o serviço prestado reclame a subordinação, a habitualidade e a pessoalidade. Seu intuito, é dimensionar a violação dos princípios da legalidade e da igualdade em virtude dessa restrição imposta às cooperativas de trabalho.

Como quarto, o Professor Leonardo Rafael de Souza, com seu texto Panorama das Cooperativas de Crédito no Brasil, oferece um panorama elucidativo sobre a realidade do Cooperativismo de crédito no Brasil, transitando pelo percurso histórico de sua constituição e desenvolvimento. Por este caminho, reflete sobre os riscos que as sociedades cooperativas de crédito correm de ter afetada sua identidade, desnaturando-se da essência da cooperatividade.

Adiante, em quinto, o Professor Paulo Roberto Cardoso Braga, através do artigo Cooperativismo de Saúde, Mais de Meio Século de Inovações e Conquistas Atento aos Princípios E Valores Cooperativos, discorre sobre as peculiaridades inerentes às sociedades cooperativas de saúde, destacando a importância da UNIMED no contexto deste ramo cooperativo.

O sexto trabalho, do Professor Marco Aurélio Bellato Kaluf, escrito com o título A Intervenção Positiva do Estado no Domínio Econômico por Meio da Forma Cooperativa, perlustra uma ideia de intervenção positiva do Estado, no ambiente cooperativo, como prerrogativa de libertação da hipossuficiência e de alcance das condições indispensáveis à conquista do status de agente ativo no âmbito da livre concorrência.

Posteriormente, como sétimo, tem-se o trabalho desenvolvido pelos Professores José Eduardo Miranda e Andréa Corrêa Lima, o qual leva o título Liberdade de Empresa, Identidade Cooperativa e Respon- 
sabilidade Social do Cooperativismo: A Redenção do Socialis et Adminicula Hominum, e percorre pelas questões que interrelacionam à liberdade de empresa, à identidade cooperativa e ao exercício da responsabilidade social, como supedâneo de resgate do socialis et adminicula hominum. A pesquisa busca confirmar que a responsabilidade social, como prerrogativa da função social das entidades econômicas de mercado, é inerente à identidade das sociedades cooperativas, as quais revelam-se fundamentais à conformação do homem social e fraterno.

Finamente, como oitavo, o Professor Guilherme Krueger, com sua produção Tierischer Als Jeder Tier (mais feroz que toda a fera): As Assembleias Gerais Digitais ou Semipresenciais em Cooperativas como Controladoras de Dados dos seus Cooperados, examina o fenômeno da tecnologia e sua influência no processo democrático, consubstanciado no desenvolvimento das Assembléias de membros, à luz das Leis 13.709/18 e 14.030/20, respectivamente a Lei Geral de Proteção de Dados (LGPD) e alteração na Lei Geral das Cooperativas, a Lei 5.764/7.

Em conjunto, todos os autores apegam-se à gênese do termo atualidades, de forma que cada trabalho traz à luz o que de mais moderno se discute no ambiente do Cooperativsimo brasileiro.

Conscientes que o estudo, a contrução dos saberes, e a produção científica não se esgotam pela construção desta obra, os colaboradores desta edição da Revista Deusto de Estudios Cooperativos subscrevem sua consciência de que a pesquisa cooperativa precisa, cada vez mais, consolidar-se dentro das Universidades brasileiras. Assinam, portanto, sua gratidão à Universidad de Deusto, e congratulações ao Instituto de Estudios Cooperativos pela iniciativa de internacionalizar uma parcela significativa do referencial teórico do Cooperativismo brasileiro

José Eduardo de Miranda Reitor do UniMB

Coordenador desta Edição da Revista Deusto Estudios Cooperativos 


\section{Derechos de autor}

http://dec.revistas.deusto.es/

La revista Deusto Estudios Cooperativos es una revista de acceso abierto lo que significa que es de libre acceso en su integridad inmediatamente después de la publicación de cada número. Se permite su lectura, la búsqueda, descarga, distribución y reutilización legal en cualquier tipo de soporte sólo para fines no comerciales y según lo previsto por la ley; sin la previa autorización de la Editorial (Universidad de Deusto) o el autor, siempre que la obra original sea debidamente citada (número, año, páginas y DOI si procede) y cualquier cambio en el original esté claramente indicado.

\section{Copyright}

The Deusto Journal of Cooperative Studies is an Open Access journal which means that it is free for full and immediate access, reading, search, download, distribution, and lawful reuse in any medium only for non-commercial purposes, without prior permission from the Publisher or the author; provided the original work is properly cited and any changes to the original are clearly indicated. 